\title{
Update concerning the impact of spirituality/ religiosity on cardiovascular disorders
}

\section{Mini Review}

The literature has investigated the relationship between spirituality/ religiosity $(\mathrm{S} / \mathrm{R})$ and cardiovascular diseases. ${ }^{1,2}$ It is well documented the difficulties related to the experimental procedures to evidence any effect. The influence of $\mathrm{S} / \mathrm{R}$ on risk factors, cardiovascular mortality and other diseases have shown conflicting results, because their relationship is extremely complex, ranging from the decision making, which is under individual's control, until genetic and environmental factors. ${ }^{1,2}$

Recent studies that evaluated the association between SR and cardiovascular system included spiritual programs and relaxation session. Previous multiple prospective cohort and case-control studies linked S/R with decreased cardiovascular mortality and morbidity. ${ }^{3,4} \mathrm{~A}$ cross-sectional research, which evaluated a rural population in India, reported that prayer and yoga events in men were associated with reduced prevalence of coronary heart disease. ${ }^{5}$ In addition, another investigation in a predominantly Moslem and Christian population evidenced that $\mathrm{S} / \mathrm{R}$ was inversely related with acute coronary events. ${ }^{6}$

The relationship between S/R and cardiovascular disorders was documented in a review ${ }^{7}$ that mentioned the positive effects of $S / R$ on reduction of cardiovascular risk factors, improvement in hypertension, inflammatory markers, coronary arterial disease, cerebrovascular disorders, cardiac surgery outcomes, overall mortality, cardiovascular mortality and cardiovascular function. Social, psychological and behavioral pathways were suggested to explain the mentioned results. The authors proposed interventions based on spirituality.

An elegant systematic review published by Luchheti et al. ${ }^{8}$ reported that the positive influence of $\mathrm{S} / \mathrm{R}$ on mortality is comparable to food intake interventions. The review also suggested that the impact of $S / R$ on cardiovascular system is higher than many health interventions indicated for therapy. The authors found decreased mortality rate in subjects that attended religious services once a week or more compared with subjects that participated in religious services less than weekly attendees. ${ }^{9}$

In summary, many studies evidenced that $\mathrm{S} / \mathrm{R}$ presents significant association with the cardiovascular system. The abovementioned references in this mini-review suggested that $S / R$ is an important factor for treatment or prevention of cardiovascular disorders, suggesting $\mathrm{S} / \mathrm{R}$ as a complementary and non-pharmacological therapy for cardiovascular diseases.
Volume 2 Issue 6 - 2018

Vitor Engrácia Valenti

Departamento de Fonoaudiologia, UNESP, Brasil

Correspondence: Vitor Engrácia Valenti, Centro de Estudos do Sistema Nervoso Autônomo (CESNA), Departamento de Fonoaudiologia, UNESP, Av. Hygino Muzzi Filho, 737, Mirante, 17.525-900 - Marília, SP, Brazil,Tel +55 (|4) 3402-I300, Email vitor.valemti@marilia.unesp.br

Received:September 20, 2017 | Published: December 04, 2018

\section{Conflicts of interest}

The authors declare there is no conflicts of interest.

\section{References}

1. Alves RR, Alves Hda N, Barboza RR, et al. The influence of religiosity on health. Cien Saude Colet. 2010;15(4):2105-2111.

2. Anyfantakis D, Symvoulakis EK, Panagiotakos DB, et al. Impact of religiosity/spirituality on biological and preclinical markers related to cardiovascular disease. Results from the SPILI III study. Hormones (Athens). 2013;12(3):386-396.

3. Chida Y, Steptoe A, Powell LH. Religiosity/spirituality and mortality. A systematic quantitative review. Psychother Psychosom. 2009;78(2):8190.

4. Oman D, Kurata JH, Strawbridge WJ, et al. Religious attendance and cause of death over 31 years. Int J Psychiatry Med. 2002;32(1):69-89.

5. Gupta R, Prakash H, Gupta VP, et al. Prevalence and determinants of coronary heart disease in a rural population of India. J Clin Epidemiol. 1997;50(2):203-209.

6. Burazeri G, Goda A, Kark JD. Religious observance and acute coronary syndrome in predominantly Muslim Albania: a population-based casecontrol study in Tirana. Ann Epidemiol. 2008;18(12):937-945.

7. Seeman TE, Dubin LF, Seeman M. Religiosity/spirituality and health. A critical review of the evidence for biological pathways. Am Psychol. 2003;58(1):53-63.

8. Lucchetti G, Lucchetti AL, Koenig HG. Impact of spirituality/religiosity on mortality: comparison with other health interventions. Explore (NY). 2011;7(4):234-238.

9. McCullough ME, Hoyt WT, Larson DB. Religious involvement and mortality: a meta-analytic review. Health Psychol. 2000;19(3):211-222.

\section{Acknowledgments}

None. 